\title{
Reply to comments by Dr. de León-Bojorge et al. on our article "Atypical teratoid/rhabdoid tumor of the central nervous system: clinicopathologic and immunohistochemical features of four cases"
}

\author{
Yeșim Ertan
}

Received: 18 June 2009 Published online: 28 July 2009

(C) Springer-Verlag 2009

\section{Dear Editor:}

Dr. de León-Bojorge et al. have recently made some comments about our article published in Child's Nervous System, entitled "Atypical teratoid/rhabdoid tumor of the central nervous system: clinicopathologic and immunohistochemical features of four cases" [1]. They have mentioned that in the paper, the authors did not find any figure related with the immunohistochemical features, as stated in the title. As the immunohistochemical features were variable among the cases, we preferred to present only the histological figures of the cases. Additionally, all of our cases were immunohistochemically INI-1 negative, the characteristic feature of atypical teratoid/rhabdoid tumors (AT/RT). We have thought that it was not valuable to print the figures of negative cases. However, we had mentioned the details of our immunohistochemical results in the text. In addition, the reviewers were confident with the results, and they did not ask for figures of the immunohistochemical study.
As the authors mentioned, we did not include the article by Dr. de León-Bojorge et al., entitled "Central nervous system atypical teratoid rhabdoid tumor: experience at the National Institute of Pediatrics, Mexico City" in the references of our paper [2]. Since it was not aimed to be a review article, we are sorry because we have not included all the published papers on AT/RTs.

\section{Reference}

1. Ertan Y, Sezak M, Turhan T, Kantar M, Ersahin Y, Mutluer S, Vergin C, Öniz H, Akalm T (2009) Atypical teratoid/rhabdoid tumor of the central nervous system: clinicopathologic and immunohistochemical features of four cases. Childs Nerv Syst 25:707-711

2. de Leon-Bojorge B, Rueda-Franco F, Anaya-Jara M (2008) Central nervous system atypical teratoid rhabdoid tumor: experience at the National Institute of Pediatrics, Mexico City. Childs Nerv Syst 26:307-312
Y. Ertan $(\bowtie)$

Department of Pathology, Ege University, School of Medicine, İzmir, Turkey

e-mail: yesim.ertan@ege.edu.tr 